\title{
Effect of gravel subgrade on hydraulic performance of geosynthetic clay liner
}

\author{
Hsin-Yu Shan ${ }^{\mathrm{a}, *}$, Ray-Ho Chen ${ }^{\mathrm{b}}$ \\ a Department of Civil Engineering, National Chiao Tung University, 1001 Ta Hsueh Road, Hsinchu, Taiwan \\ ${ }^{\mathrm{b}}$ Megic Inc., Hsinchu Science Based Industrial Park, Hsinchu, Taiwan
}

Received 22 March 2003; received in revised form 13 May 2003; accepted 18 May 2003

\begin{abstract}
The effect of a gravel subgrade on the hydraulic performance of GCLs is investigated. Laboratory test results show that the GCL specimens exhibit significant variation in thickness when compressed against gravel. The maximum and minimum thicknesses of the specimen were about 20 and $3 \mathrm{~mm}$, respectively, after consolidation by an effective stress up to $138 \mathrm{kPa}$. However, the permittivity of GCLs remained very low. The permittivity of both needlepunched and adhesive-bonded geotextile-supported GCLs decreased with increasing confining stress, regardless of the type of subgrade materials. In general, larger particles led to more significant migration of bentonite. Nevertheless, there was no significant difference in the degree of bentonite migration between the two GCLs investigated.
\end{abstract}

(C) 2003 Elsevier Ltd. All rights reserved.

Keywords: Geosynthetic clay liner; Gravel; Subgrade; Landfill

\section{Introduction}

GCLs have been used for lining landfills, surface impoundments, canals, and all kinds of ponds. The low hydraulic conductivity of thin layers of bentonite in GCLs makes them more impermeable than compacted clay liners (CCLs). However, the hydrated bentonite is highly compressible and has very low shear strength, especially under low effective stress. Furthermore, the thickness of GCLs has always generated concerns over their survivability in the field. One of the important issues that still generate a lot of attention and skepticism is that when large-size particles are pressed

*Corresponding author. Tel.: + 886-3-513-1562; fax: + 886-3-571-6257.

E-mail addresses: hyshan@mail.nctu.edu.tw (H.-Y. Shan), finderchen@megic.com.tw (R.-H. Chen). 
against GCLs, the bentonite in the contacting areas is likely to be pushed aside and the GCL will be thinner; in more severe conditions, the GCLs may be punctured.

Although lot of field case histories reported successful applications of GCLs when QA/QC procedures have been carefully followed, laboratory studies on the ability of GCLs to withstand rough subgrade have not been as many. Laboratory tests conducted by Shan and Daniel (1991) demonstrated that GCLs do have certain ability to self-seal the small holes caused by puncturing. Koerner and Narejo (1995) have studied the bearing capacity of GCLs using laboratory CBR test equipment. Their results showed that as the size of particles of the cover soil increased, there was more migration of bentonite. This caused the thickness of the GCLs become less uniform. Moreover, it was found that the ability of needle-punched GCLs to resist deformation was better than adhesive-bonded GCLs. As a result, the authors suggested that it is necessary to use thicker soil cover to protect the GCLs. Further studies on the migration of bentonite under rapidly applied concentrated loads and areal loads have been conducted by Fox et al. (1996), Anderson (1996), and Stark (1998).

Peggs and Olsta (1998) reported the failure of a GCL lined wastewater lagoons. The needle-punched GCL was placed on a subgrade of coarse gravel and cobbles and then covered with the same coarse soil. The earthwork operation of a heavy bulldozer produced holes as large as $40 \mathrm{~mm}$ in the GCL and the lagoons could not hold the wastewater. On the other hand, Fox et al. (1998) carried out a series of field tests in order to evaluate the degree of damage done on the GCLs during field installation. During the tests, the bulldozers traveled back and forth on soil covers of different thickness under which the GCLs were laid. Later the GCLs were retrieved from the field and tested in the laboratory. The results indicated that the needlepunched GCLs were less affected by the operation as judged by the hydraulic conductivity of the specimens.

More recently, the results of experiments conducted by Fox et al. (2000) showed that the hydraulic performance of GCLs covered with gravel was not significantly impacted. The GCL specimens with gravel on top were tested in $152 \mathrm{~mm}$ (6-in) diameter flexible-wall permeameters. The size of the gravel ranged from 12.7 (0.5 in) to $50.8 \mathrm{~mm}$ (2.0 in). A needle-punched GCL and an adhesive-bonded GCL were tested. The results showed that the hydraulic conductivity, permittivity, and difference of thickness of GCLs increased with the size of the gravel. In addition, the water content in the peak and the valley of the specimen showed a significant difference. The variation of mass per unit area of the two GCLs indicated that the bentonite in the needle-punched GCL was less likely to be squeezed and displace laterally than the adhesive-bonded GCL. The hydraulic conductivity and permittivity of needle-punched GCL were lower than that of the adhesive-bonded GCL at low effective stress, but under high effective stress there was no such difference.

These results are very encouraging since the effectiveness of GCLs placed against large size particles was always a serious question when discussing the equivalency of GCLs and the CCLs. However, the size of the GCL specimens the authors used was $152 \mathrm{~mm}$ while the maximum size of the gravel particle was $50.8 \mathrm{~mm}$. The ratio of the 
diameter of the GCL specimen to the diameter of the largest gravel particle was 3 which was considerably less than 6 , which is usually suggested for many geotechnical laboratory tests. As a result, the effect of large size particles on the hydraulic performance of GCLs warrants further investigation.

Rowe and Orsini $(2002,2003)$ looked into the internal erosion GCLs when placed on different types of subgrade material. The results showed that internal erosion caused by high hydraulic gradient took place, and the hydraulic conductivity increased at least 10-fold when GCLs with conventional woven or nonwoven carrier geotextiles were placed on gravel or geonets. However, internal erosion did not occur either using GCLs with a scrim-reinforced nonwoven geotextile layer or placing GCLs on a sand subgrade even when the applied water heads were up to $70 \mathrm{~m}$. These results raise additional concerns of how GCLs perform when placed on gravel subgrade.

\section{Experimental program}

\subsection{Gcls, gravel, and stones}

The GCLs tested in this study are Bentomat ${ }^{\circledR}$ ST and Claymax ${ }^{\circledR} 200 \mathrm{R}$, which are designated as GCL-A and GCL-B, respectively. GCL-A is comprised of a nonwoven needle-punched geotextile that is needle-punched through a layer of bentonite into a woven slit-film geotextile. The bentonite content is $3.6 \mathrm{~kg} / \mathrm{m}^{2}$. The water content of the bentonite in dry GCL-A is about $10-12 \%$. In the adhesive-bonded GCL-B, $3.6 \mathrm{~kg} / \mathrm{m}^{2}$ of bentonite is sandwiched between woven geotextile on the top and open weave geotextile at the bottom. The thickness of both GCLs is about $6 \mathrm{~mm}$ when they are dry. The properties of the GCLs are listed in Table 1.

Two types of granular materials were used in this study. The first one was crushed stone of diameter ranging from 25.4 ( 1 in) to $50.8 \mathrm{~mm}(2 \mathrm{in})$. The shape of the stones

Table 1

Properties of GCLs samples (CETCO, 1998a, b)

\begin{tabular}{|c|c|c|c|}
\hline \multirow[t]{2}{*}{ Property } & \multirow[t]{2}{*}{ Test method } & \multicolumn{2}{|l|}{ Required values } \\
\hline & & GCL-A & GCL-B \\
\hline Bentonite Swell Index & ASTM D 5890 & $24 \mathrm{ml} / 2 \mathrm{~g} \min$ & $24 \mathrm{ml} / 2 \mathrm{~g} \min$ \\
\hline Bentonite Fluid Loss & ASTM D 5891 & $18 \mathrm{ml} / \max$ & $18 \mathrm{ml} / \max$ \\
\hline Bentonite Mass/Area & ASTM D 5993 & $3.6 \mathrm{~kg} / \mathrm{m}^{2}$ & $3.6 \mathrm{~kg} / \mathrm{m}^{2}$ \\
\hline GCL Grab Strength & ASTM D 4632 & $400 \mathrm{~N}$ & $330 \mathrm{~N}$ \\
\hline GCL Peel Strength & ASTM D 4632 & $65 \mathrm{~N}$ & $\mathrm{~N} / \mathrm{A}$ \\
\hline GCL Index Flux ${ }^{a}$ & ASTM D 5887 & $1 \times 10^{-8} \mathrm{~m}^{3} / \mathrm{m}^{2} / \mathrm{s}$ & $1 \times 10^{-8} \mathrm{~m}^{3} / \mathrm{m}^{2} / \mathrm{s}$ \\
\hline GCL Permeability $^{\mathrm{a}}$ & ASTM D 5084 & $5 \times 10^{-9} \mathrm{~cm} / \mathrm{s}$ & $5 \times 10^{-9} \mathrm{~cm} / \mathrm{s}$ \\
\hline GCL Hydrated Internal Shear Strength & ASTM D 5321 & $24 \mathrm{kPa}$ typical & $2.4 \mathrm{kPa}$ typical \\
\hline
\end{tabular}

\footnotetext{
${ }^{\mathrm{a}}$ Tests performed with deaired distilled water, confining pressure, head water pressure, and tailwater pressure were 551,531 , and $517 \mathrm{kPa}$, respectively.
} 


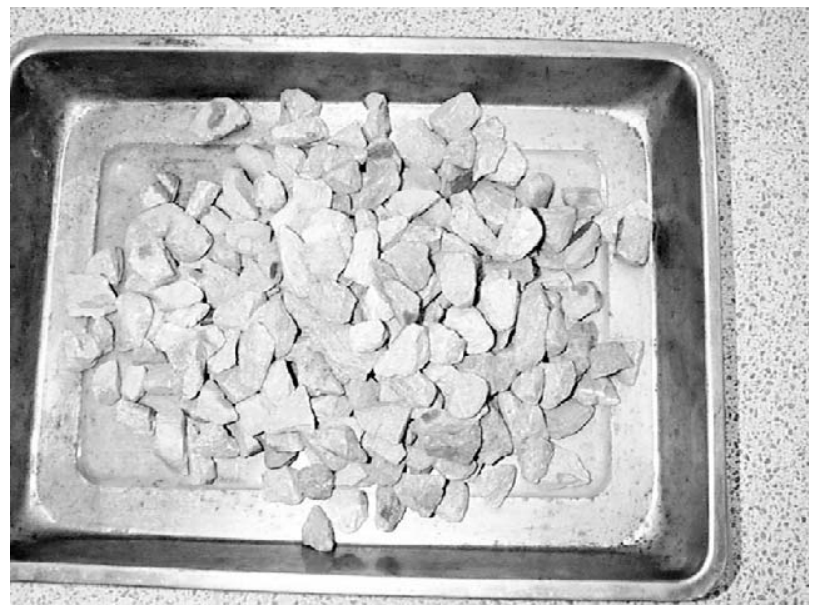

Fig. 1. Crushed stones with diameter ranging from 25.4 ( 1 in) to $50.8 \mathrm{~mm}$ ( 2 in).

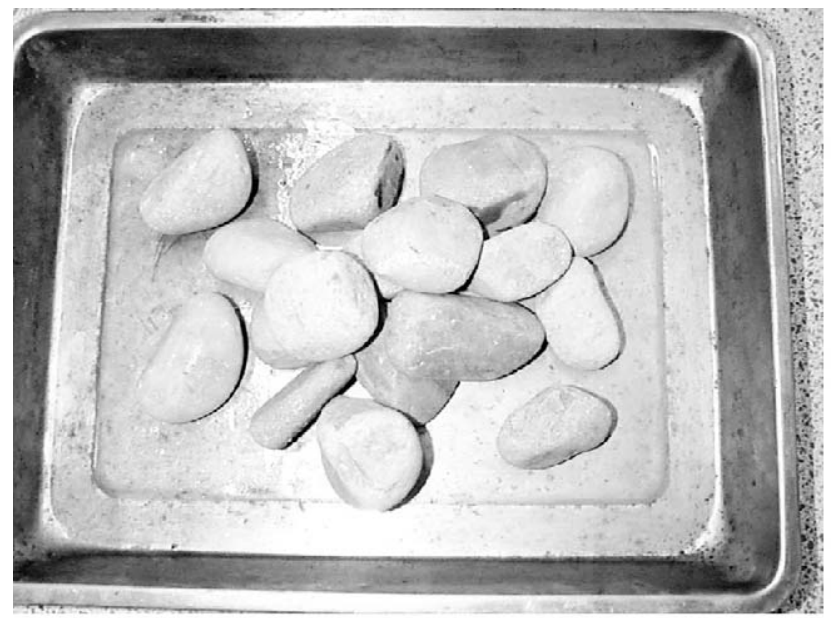

Fig. 2. Gravel with diameter ranging from 50.8 (2 in) to $76.2 \mathrm{~mm}(3 \mathrm{in})$.

could be categorized as ranging from subangular to angular (Fig. 1). The other one was gravel of diameter between 50.8 ( 2 in) to $76.2 \mathrm{~mm}$ ( 3 in). The shape of the gravel ranged from subrounded to round (Fig. 2).

\subsection{Permeameter and testing procedure}

The schematic diagram of the permeameter and a photograph of the disassembled parts are shown in Figs. 3 and 4, respectively. The effective normal stress applied on GCL specimens was provided by static water pressure on the piston. The inner diameter of the permeameter was $300 \mathrm{~mm}$. The height of both the upper and the 


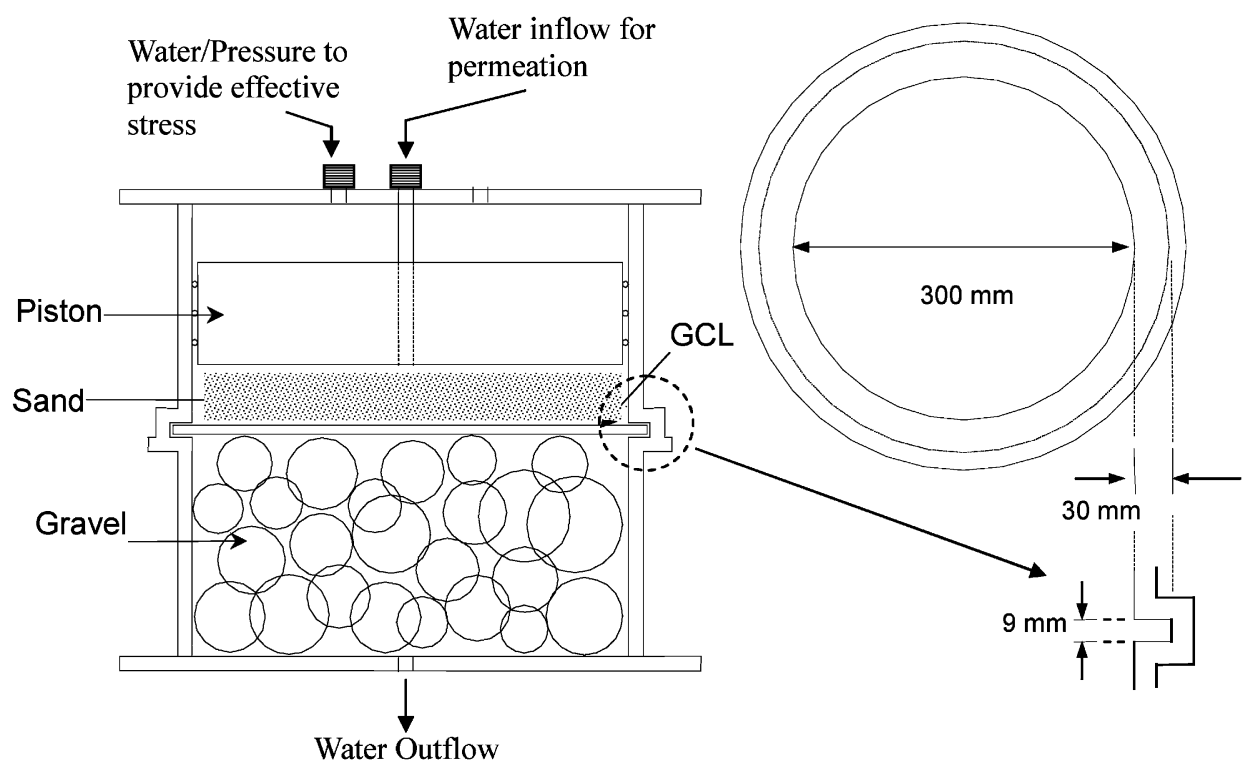

Fig. 3. Schematic diagram of the permeameter.

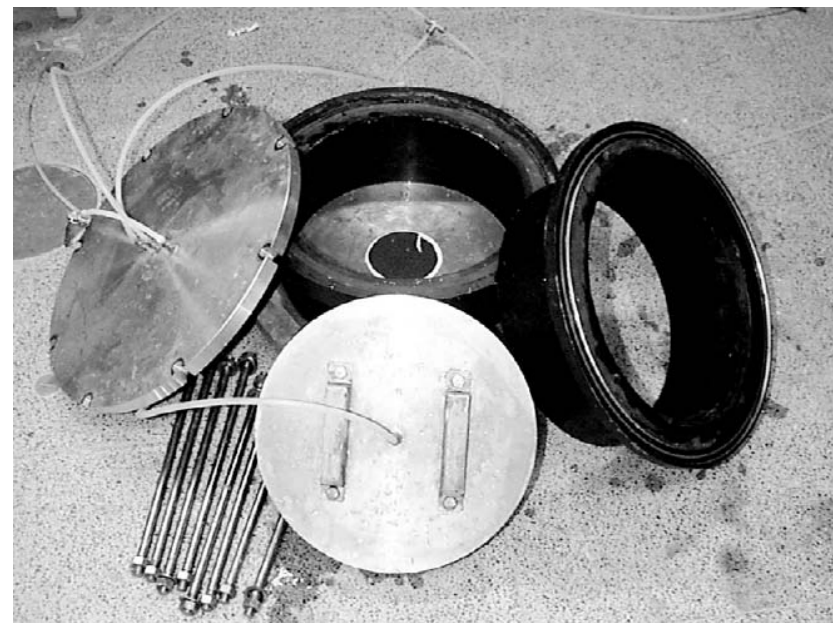

Fig. 4. Dissembled permeameter.

lower half of the permeameter was $150 \mathrm{~mm}$. The GCL specimen was supported by the subgrade material that filled the lower half of the permeameter while its edges were inside the ring. The diameter and the height of the annular space in the ring were 360 and $9.0 \mathrm{~mm}$, respectively. The annular space allowed the GCL specimen to be able to displace laterally. Bentonite powder was spread above and below the edge of GCL specimen to prevent leakage. 
Table 2

Subgrade materials and applied effective stress used in the tests

\begin{tabular}{lllll}
\hline Test no. & Specimen & Subgrade material & $\begin{array}{l}\text { Initial effective } \\
\text { stress }(\mathrm{kPa})\end{array}$ & $\begin{array}{l}\text { Effective stress } \\
\text { sequence }(\mathrm{kPa})\end{array}$ \\
\hline No. 1 & GCL-A-1 & Sand & 13.8 & $13.8-34.5-69-138$ \\
No. 2 & GCL-A-2 & Crushed stone & 13.8 & $13.8-69-138$ \\
No. 3 & GCL-A-3 & Crushed stone & 34.5 & $34.5-69-138$ \\
No. 4 & GCL-A-4 & Gravel & 34.5 & $34.5-69-138$ \\
No. 5 & GCL-B-1 & Sand & 13.8 & $13.8-34.5-69-138$ \\
No. 6 & GCL-B-2 & Crushed stone & 13.8 & $13.8-69-138$ \\
No. 7 & GCL-B-3 & Crushed stone & 34.5 & $34.5-69-138$ \\
No. 8 & GCL-B-4 & Gravel & 34.5 & $34.5-69-138$ \\
\hline
\end{tabular}

For each permeation test the lower half of the chamber was first filled with subgrade material and water. The GCL specimens with a diameter of $360 \mathrm{~mm}$ were placed on the subgrade material after bentonite paste was spread along the inner rim of the annular space. After the upper chamber had been put in place, a $30-\mathrm{mm}$ thick layer of coarse sand was placed on top of the GCL specimen. The nonwoven geotextile side of GCL-A and open weave geotextile side of GCL-B was placed against the gravel or stone subgrade. The whole test chamber was then assembled and the GCL specimens were allowed to hydrate under the predetermined effective stress.

A total of eight series of tests were performed. The combinations of GCLs and subgrade materials are listed in Table 2. The initial effective stress under which GCL specimens hydrated was 13.8 and $34.5 \mathrm{kPa}$. The maximum effective stress was $138 \mathrm{kPa}$. This effective stress is representative of the overburden generated by 15-20 m high of consolidated solid waste. The head difference of water across the GCL specimen was maintained at approximately $0.69 \mathrm{~m}(6.9 \mathrm{kPa}$ of pressure difference). This head difference generated a hydraulic gradient, $i$, of about 70 .

Since the test chamber was quite large, the volume change within a day could reach as much as $2 \mathrm{ml}$, the volumes of influent and effluent water were recorded at approximately same time everyday to minimize the error induced by temperature effect.

The results of permeation tests are reported in terms of permittivity, $\psi$, defined as

$$
\psi=\frac{k}{t},
$$

where $k$ is the hydraulic conductivity of GCL, and $t$ is the thickness of GCL. Permittivity can be computed as follows:

$$
\psi=\frac{q}{\Delta h A},
$$

where $q$ is the measured flow rate, $\Delta h$ is the head difference across the geosynthetic material tested, and $A$ is the area of flow. 
Thickness of the GCL specimens was measured after each test. The thickness was determined by measuring the penetration of a needle inserted into the specimens. The measurement was carried out immediately after the GCL specimens had been retrieved from the test cells so that the swelling of specimens due to relieve of effective stress could be minimized. Thus, the thickness of each specimen should represent the thickness under the effective stress for the final stage of permeation, which was $138 \mathrm{kPa}$. For every specimen, a total of 60 measurements were made at positions distributed evenly over the entire area. Areas where judged to be extraordinarily thick or thin were also included in the 60 measurements.

The distribution of the mass per unit area of each specimen was also determined. A brass ring with an inner diameter of $33.0 \mathrm{~mm}$ was used to take bentonite samples from the GCL specimens for measurement of their mass. For GCL-A, the bentonite and the geotextiles were tangled together by needle-punched fibers. The dimensions of the samples were measured and the weight of the whole oven-dried samples, including the bentonite, the geotextiles, and the needle-punched fibers were determined. Thus, the numbers reported include the weight of the geotextiles and the fibers. On the other hand, for GCL-B, whose geotextiles could be separated from the bentonite easily, the geotextile on one side of the specimens was peeled off and then the bentonite samples were taken by pushing the brass ring into the bentonite. The bentonite was then removed from the brass ring, put in weighing cans, and ovendried. The mass per unit area for GCL-B refers to the mass of bentonite alone.

\section{Results and discussion}

\subsection{Thickness}

Average values and standard deviations of the thickness of the specimens are listed in Table 3. Among all GCL-A specimens, GCL-A-2 had the maximum standard deviation of thickness, which was $3.39 \mathrm{~mm}$. Although the size of the gravel used in

Table 3

Thickness of GCL specimens measured after permeation

\begin{tabular}{lllllllll}
\hline $\begin{array}{l}\text { Test } \\
\text { no. }\end{array}$ & Specimen & Subgrade & $\begin{array}{l}\text { Maximum } \\
\text { thickness } \\
(\mathrm{mm})\end{array}$ & $\begin{array}{l}\text { Minimum } \\
\text { thickness } \\
(\mathrm{mm})\end{array}$ & $\begin{array}{l}\text { Maximum } \\
\text { difference } \\
(\mathrm{mm})\end{array}$ & $\begin{array}{l}\text { Average } \\
\text { thickness } \\
(\mathrm{mm})\end{array}$ & $\begin{array}{l}\text { Standard } \\
\text { deviation } \\
(\mathrm{mm})\end{array}$ & $\begin{array}{l}\text { Standard } \\
\text { deviation } \\
(\%)\end{array}$ \\
\hline No. 1 & GCL-A-1 & Sand & 11.7 & 9.8 & 1.9 & 10.0 & 0.43 & 4.3 \\
No. 2 & GCL-A-2 & Crushed stone & 20 & 5 & 15 & 10.1 & 3.39 & 33.56 \\
No. 3 & GCL-A-3 & Crushed stone & 17 & 5 & 12 & 10.25 & 2.34 & 22.83 \\
No. 4 & GCL-A-4 & Gravel & 20 & 3 & 17 & 9.85 & 3.20 & 32.49 \\
No. 5 & GCL-B-1 & Sand & 11.9 & 9.7 & 2.2 & 9.7 & 0.45 & 4.5 \\
No. 6 & GCL-B-2 & Crushed stone & 18 & 4 & 14 & 9.72 & 3.24 & 33.33 \\
No. 7 & GCL-B-3 & Crushed stone & 17 & 4 & 13 & 9.67 & 2.75 & 28.44 \\
No. 8 & GCL-B-4 & Gravel & 18 & 3 & 15 & 9.57 & 3.31 & 34.59 \\
\hline
\end{tabular}


test No. 4 is larger, the standard deviation of GCL-A-4 was not the highest among all GCL-A specimens. The greater variation of the thickness of GCL-A-2 resulted from the angular shape of the crushed stones. In addition, the lower initial effective stress under which GCL-A-2 hydrated was the reason that it had a significantly larger standard deviation than that of GCL-A-3 $(2.34 \mathrm{~mm})$. Under lower effective stress, the compressibility of bentonite was higher and thus displaced more when pushed against by the intruding stones.

In contrast, for GCL-A-3, which hydrated under an effective stress of $34.5 \mathrm{kPa}$, the bentonite swelled less to conform to the irregular surface underneath. It was likely that the swelling pressure caused the bentonite that rested against the stones to have higher density than the bentonite in GCL-A-2. As a result, the bentonite had a larger resistance to lateral displacement caused by further pushing of the stones such that the thickness of GCL-A-3 had a more uniform distribution than GCL-A-2 (Fig. 5). This also explains the difference between the standard deviation of thickness of GCL-B-2 and GCL-B-3, which are 3.24 and $2.75 \mathrm{~mm}$, respectively. The distribution of thickness measured on GCL-B-2 and GCL-B-3 is shown in Fig. 6. It can be concluded that the higher the effective stress under which the GCL hydrates, the less the variation of the thickness.

The standard deviation of the 60 measured values of thickness of GCL-A-4 was $3.20 \mathrm{~mm}$ and was $37 \%$ higher than the $2.34 \mathrm{~mm}$ for GCL-A-3. The comparison of the results of GCL-A-4 to GCL-A-3, which hydrated under the same effective stress, indicates that the larger size of the gravel did result in a less uniform distribution of bentonite (Fig. 7). In particular, the maximum and minimum values for GCL-A-3 were 20 and $3.0 \mathrm{~mm}$, respectively. The large indented zones created by the gravel are shown in Fig. 8.

The comparison of the results for specimens GCL-B-3 and GCL-B-4 led to exactly the same conclusions as those for GCL-A-3 and GCL-A-4. The standard deviation of thickness of GCL-B-4 was 3.31 and was $20 \%$ greater than the $2.75 \mathrm{~mm}$ for

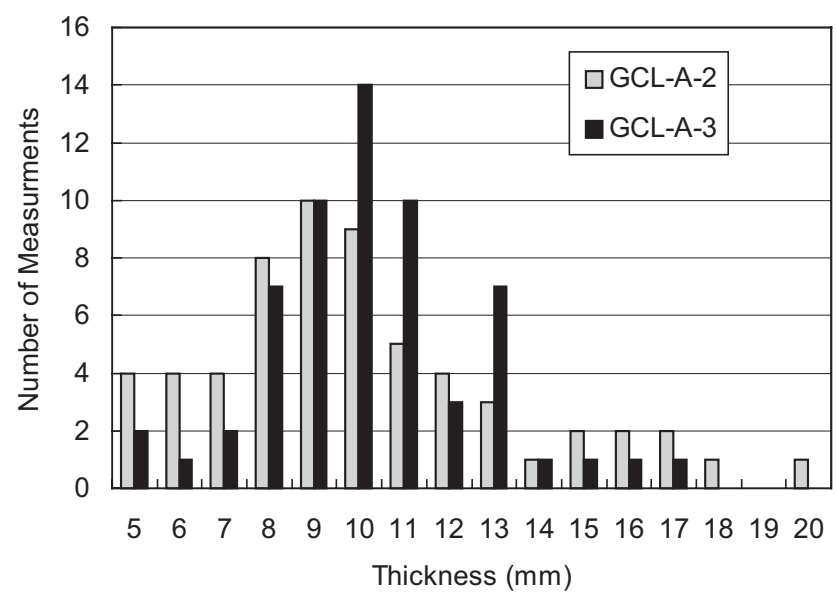

Fig. 5. Distribution of thickness of specimens GCL-A-2 and GCL-A-3. 


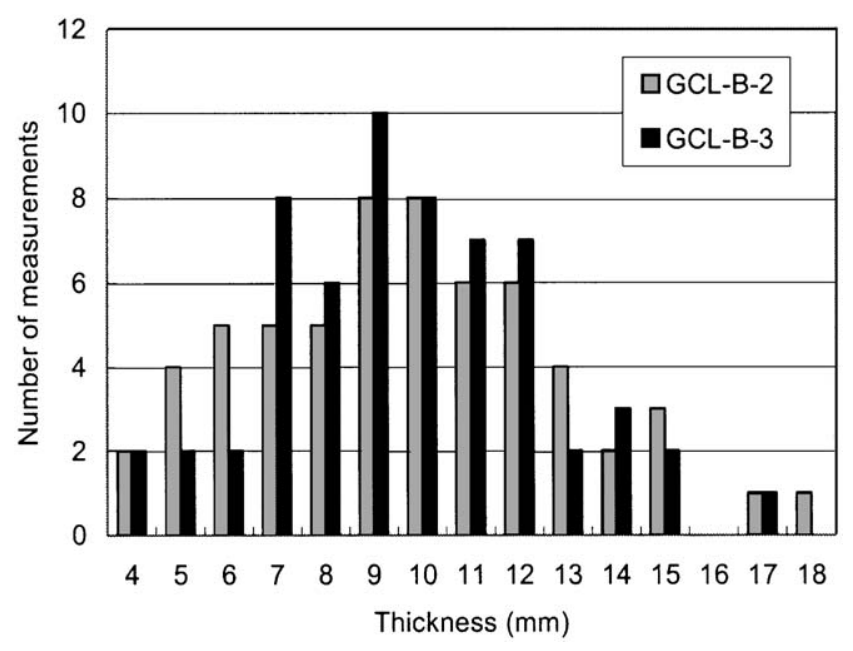

Fig. 6. Distribution of thickness of specimens GCL-B-2 and GCL-B-3.

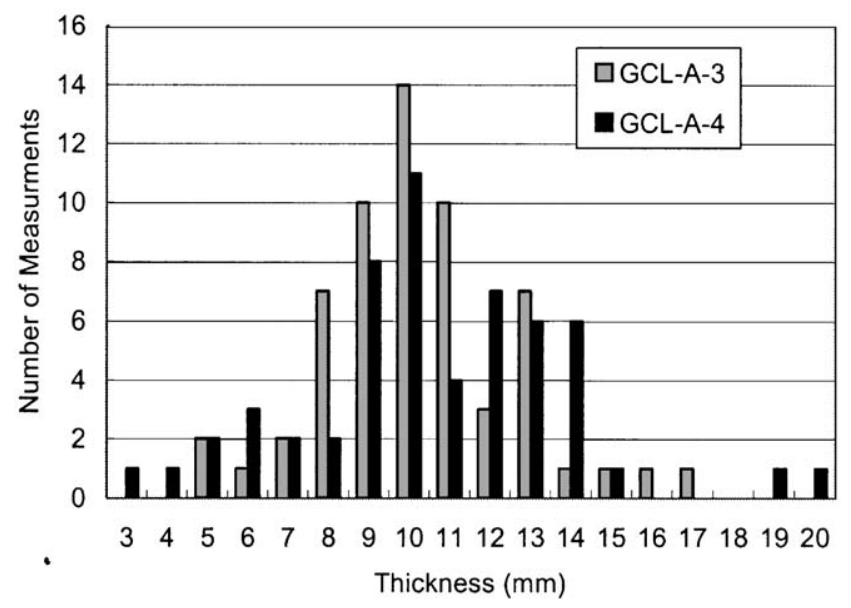

Fig. 7. Distribution of thickness of specimens GCL-A-3 and GCL-A-4.

GCL-B-3. The variation of thickness of GCL-B-3 and GCL-B-4 is shown in Fig. 9. The deformation of the GCL-B-4 specimen caused by the gravel is shown in Fig. 10 .

The maximum differences of thickness for both GCLs are similar judging from the variation of thickness of samples of two GCLs. Under an effective stress of $138 \mathrm{kPa}$, the maximum difference of thickness ranged from 12 to $17 \mathrm{~mm}$. Moreover, the larger-size gravel subgrade induced larger maximum difference of thickness than crushed stone despite the fact that the crushed stones have a more angular shape.

On the other hand, after examination of the distribution of thickness shown in Figs. 5-7, 9, it is noted that the variation of the thickness over the whole specimens for GCL-B was less significant than GCL-A. This is contradictory with what was 


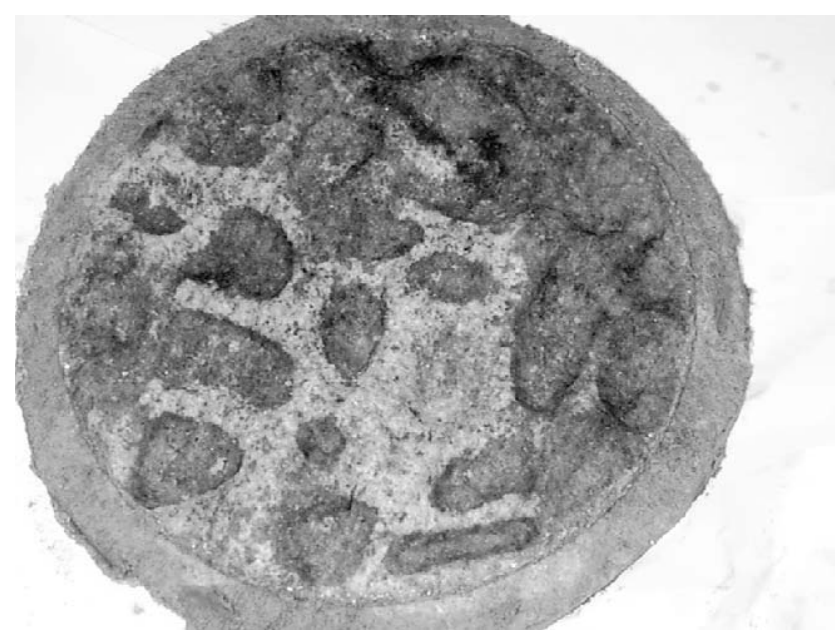

Fig. 8. Specimen GCL-A-4 after permeability test.

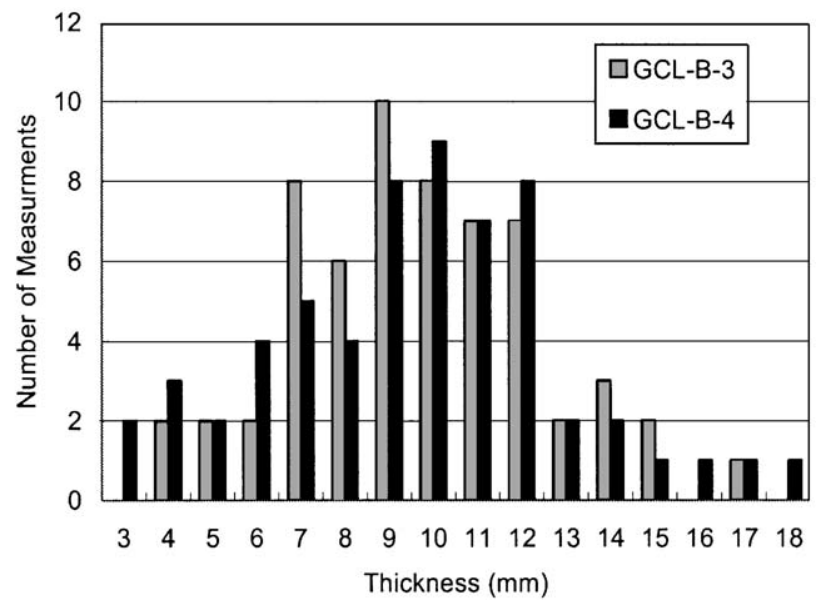

Fig. 9. Distribution of thickness of specimens GCL-B-3 and GCL-B-4.

expected since GCL-A has reinforcing fibers which could limit the expansion of the specimen and obstruct the displacement of the bentonite. Nevertheless, the results demonstrated no significant difference between the two GCLs.

By comparing the results of GCL-A-2 and GCL-B-2 to the experimental results reported by Fox et al. (2000), it was found that both the maximum thickness and the standard deviation measured in this study were twice as large as those compressed by "coarse gravel" used by Fox et al. (2000). On the other hand, although the maximum thicknesses of GCL-A-3 and GCL-B-3 were almost twice, the standard deviation was only $50 \%$ greater than those reported by Fox et al. (2000). The angular shape of crushed stone used in this study is the reason for the significant difference. 


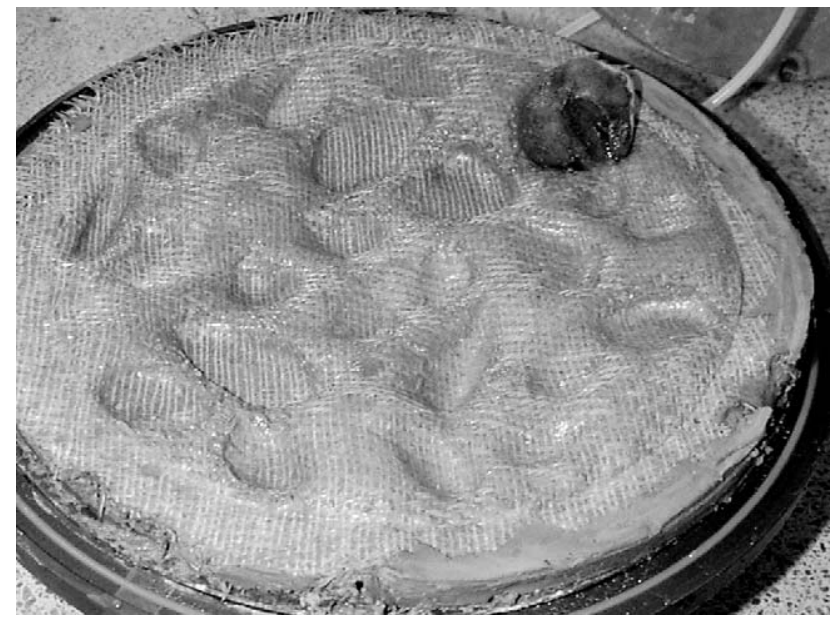

Fig. 10. Specimen GCL-B-4 after permeability test.

For GCL-A-4 and GCL-B-4, the values the standard deviation and the maximum difference of the thickness are two to three times greater than those obtained by Fox et al. (2000) from tests using "coarse" gravel of 25.4 to $50.8 \mathrm{~mm}$ in diameter. The larger size of the gravel particles obviously caused the GCLs to deform more.

\subsection{Mass per unit area}

The results on the variation of mass per unit area of the specimens are similar to the variation of their thickness. However, since the measured mass per unit area represented the average values over certain areas, both the maximum difference and the standard deviation of mass per unit area are less significant than those of thickness distribution. The standard deviation mass per unit area was about $10 \%$ (Table 4) of the average value, while the standard deviation of thickness was approximately $30 \%$. Furthermore, the percentile standard deviations of GCL-A and GCL-B were very close. Again, judging from the results, it can be concluded that the uniformity of distribution of bentonite in GCL-A and GCL-B is basically the same.

In contrast, Fox et al. (2000) concluded that the bentonite in the needle-punched GCL was less likely to be squeezed and move laterally than adhesive-bonded GCL. The main reason for the disagreement should be the difference of the boundary condition. The GCL specimens in this study had a sand layer on top such that certain degree of deformation was allowed, while in the study conducted by Fox et al. (2000), the GCLs specimens were compressed against a rigid porous disc. From the photographs shown in Figs. 8 and 10, it can be seen that GCL-B deformed more than GCL-A, which, in turns, means that more bentonite were pushed into the sand cover above (Fig. 11). Thus less bentonite was squeezed aside than when a porous disc instead of the sand layer had been placed directly on top of GCL-B specimens. 
Table 4

Variation of mass per unit area over GCL specimens after permeation

\begin{tabular}{lllllllr}
\hline Test no. & Specimen & Subgrade & $\begin{array}{l}\text { Maximum } \\
\text { value } \\
\left(\mathrm{g} / \mathrm{cm}^{2}\right)\end{array}$ & $\begin{array}{l}\text { Minimum } \\
\text { value } \\
\left(\mathrm{g} / \mathrm{cm}^{2}\right)\end{array}$ & $\begin{array}{l}\text { Average } \\
\left(\mathrm{g} / \mathrm{cm}^{2}\right)\end{array}$ & $\begin{array}{l}\text { Standard } \\
\text { deviation } \\
\left(\mathrm{g} / \mathrm{cm}^{2}\right)\end{array}$ & $\begin{array}{l}\text { Standard } \\
\text { deviation } \\
(\%)\end{array}$ \\
\hline No. 1 & GCL-A-1 & Sand & 0.60 & 0.57 & 0.589 & 0.0016 & 2.8 \\
No. 2 & GCL-A-2 & Crushed stone & 0.69 & 0.53 & 0.587 & 0.0587 & 10.00 \\
No. 3 & GCL-A-3 & Crushed stone & 0.68 & 0.54 & 0.590 & 0.0523 & 8.86 \\
No. 4 & GCL-A-4 & Gravel & 0.68 & 0.54 & 0.591 & 0.0585 & 9.89 \\
No. 5 & GCL-B-1 & Sand & 0.45 & 0.43 & 0.440 & 0.0014 & 3.2 \\
No. 6 & GCL-B-2 & Crushed stone & 0.53 & 0.40 & 0.447 & 0.0448 & 10.02 \\
No. 7 & GCL-B-3 & Crushed stone & 0.48 & 0.37 & 0.425 & 0.0383 & 9.01 \\
No. 8 & GCL-B-4 & Gravel & 0.50 & 0.37 & 0.432 & 0.0479 & 11.09 \\
\hline
\end{tabular}

Note: Mass per unit area was the average of 15 measurement.
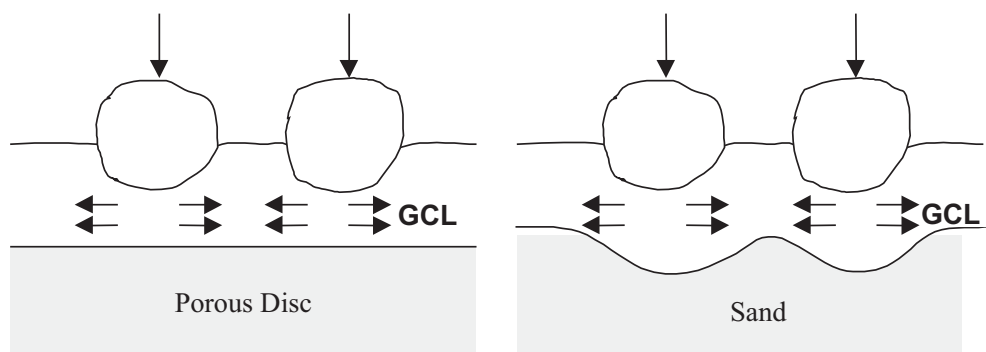

Fig. 11. Deformation pattern of GCL placed against rigid and flexible materials.

\subsection{Permittivity}

The variation of permittivity with effective normal stress for GCL-A and GCL-B are listed in Table 5 and depicted in Fig. 12, respectively. For both GCLs, the permittivity decreased with increasing effective normal stress regardless of the type of subgrade material.

For GCL-A, the permittivity of all specimens was almost the same under normal stress from 34.5 to $138 \mathrm{kPa}$. The permittivity of GCL-A-3 and GCL-A-4 was almost the same as that of GCL-A-1 under all effective stress. On the other hand, for GCL-A-2, on which the initial effective normal stress was $13.8 \mathrm{kPa}$, the permittivity was twice as large as the results of other tests at the beginning. Nevertheless, the permittivity decreased rapidly when effective normal stress increased. It seems that the bentonite in GCL-A-2, which was hydrated under a lower effective stress, underwent more lateral displacement when compressed. As indicated previously the distribution of bentonite in GCL-A-2 was less uniform than in GCL-A-3 and GCLA-4, thus the areas with thinner bentonite would certainly yield a higher liquid flux, and vice versa. However, it seems that, as the effective stress continued to increase, the effect of uniform distribution of bentonite was outweighed by the effect of 
Table 5

Permittivity of GCL specimens tested

\begin{tabular}{|c|c|c|c|c|c|c|}
\hline \multirow[t]{2}{*}{ Test no. } & \multirow[t]{2}{*}{ Specimen } & \multirow[t]{2}{*}{ Subgrade } & \multicolumn{4}{|c|}{ Permittivity (1/s) } \\
\hline & & & $13.8 \mathrm{kPa}$ & $34.5 \mathrm{kPa}$ & $69 \mathrm{kPa}$ & $138 \mathrm{kPa}$ \\
\hline No. 1 & GCL-A-1 & Sand & $3.9 \times 10^{-9}$ & $3.7 \times 10^{-9}$ & $3.3 \times 10^{-9}$ & $2.4 \times 10^{-9}$ \\
\hline No. 2 & GCL-A-2 & Crushed stone & $6.4 \times 10^{-9}$ & - & $4.8 \times 10^{-9}$ & $2.4 \times 10^{-9}$ \\
\hline No. 3 & GCL-A-3 & Crushed stone & - & $3.7 \times 10^{-9}$ & $3.5 \times 10^{-9}$ & $2.4 \times 10^{-9}$ \\
\hline No. 4 & GCL-A-4 & Gravel & - & $3.5 \times 10^{-9}$ & $3.2 \times 10^{-9}$ & $2.5 \times 10^{-9}$ \\
\hline No. 5 & GCL-B-1 & Sand & $5.8 \times 10^{-9}$ & $3.8 \times 10^{-9}$ & $3.1 \times 10^{-9}$ & $1.3 \times 10^{-9}$ \\
\hline No. 6 & GCL-B-2 & Crushed stone & $5.1 \times 10^{-9}$ & - & $5.0 \times 10^{-9}$ & $2.5 \times 10^{-9}$ \\
\hline No. 7 & GCL-B-3 & Crushed stone & - & $7.0 \times 10^{-9}$ & $4.1 \times 10^{-9}$ & $2.9 \times 10^{-9}$ \\
\hline No. 8 & GCL-B-4 & Gravel & - & $3.3 \times 10^{-9}$ & $2.6 \times 10^{-9}$ & $1.2 \times 10^{-9}$ \\
\hline
\end{tabular}

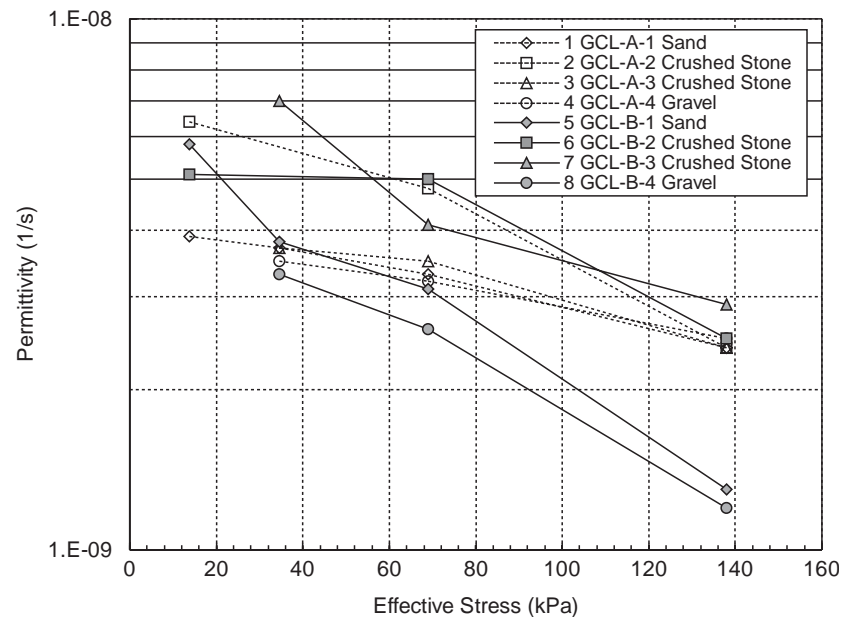

Fig. 12. Permittivity of GCL specimens.

consolidation. As a result, under an effective stress of $138 \mathrm{kPa}$, all GCL-A specimens had approximately the same permittivity. The needle-punching fibers and the thicker geotextiles of GCL-A helped limit the deformation while still allowed the stones to make good contact with the specimens.

On the contrary, the size and shape of subgrade material had a more noticeable effect on the permittivity of GCL-B (Fig. 12). The permittivity of GCL-B-2 and GCL-B-3, which was tested with crushed-stone subgrade, was higher than that of the other two GCL-B specimens. The permittivity of GCL-B laid on the crushed stones (GCL-B-2 and GCL-B-3) was about twice as high as the other two GCL-B specimens. The angular shape of the crushed stone and the resulting larger space between them left more room for bentonite to displace laterally and swell vertically. This effect is illustrated by the higher average thickness values (Table 3). The lessdensely packed bentonite thus resulted in higher hydraulic conductivity. As a result, 
in these two specimens there was larger area of higher hydraulic conductivity thus resulting in a higher permittivity. Furthermore, the permittivity of GCL-B-2 was higher than that of GCL-B-3 under $69 \mathrm{kPa}$. This finding is similar to that for GCLA-2 and GCL-A-3. Again, the lower initial effective stress during hydration was the major cause.

It is interesting to note that the permittivity of GCL-B placed on gravel (GCL-B-4) had the lowest permittivity values through out the range of effective normal stress applied. One possible reason for this result is that since GCL-B does not have needlepunched fibers, the bentonite could displace much more easily, since both the thickness and mass per unit area of GCL-B-4 had the highest percentile standard deviation. The consolidation of GCL in the large areas in contact with gravel was probably the main reason for the low permittivity.

Similar to GCL-A, the permittivity of all GCL-B specimens decreased with the increasing effective normal stress. However, the effect of the size and shape of subgrade material on the permittivity of GCL-B was more significant than GCL-A through out the range of effective stress tested. Furthermore, the difference in permittivity of the specimens of GCL-B did not seem to diminish as the effective stress increased. To sum up, it is obvious that although both GCLs maintained their low permittivity in all of the tests, GCL-A performed much more consistently than GCL-B (Fig. 12). In other words, the subgrade condition had a larger effect on the permittivity of GCL-B. The needle-punched fibers and the thicker geotextiles of GCL-A might have reduced the lateral migration of bentonite by their interference with the bentonite particles but also have limited the increase of thickness in the voids.

The internal erosion of GCLs which lead to the increase of hydraulic conductivity reported by Rowe and Orsini $(2002,2003)$ was not observed in this study although the particles size of gravel created openings of sizes much larger than those of $6 \mathrm{~mm}$ gravel and geonet. The major reason is that the water head used in this study was only $0.69 \mathrm{~m}$ which did not generate a large enough seepage force to cause serious internal erosion during the time period of the tests. However, if higher hydraulic gradient was applied and the tests lasted long enough, internal erosion may be lead to higher permittivity. However, in the field there are finer materials such as sandy or silty soils filling the pores between gravel such that the internal erosion may be hindered.

\section{Practical implications}

The preparation of a smooth subgrade is an important requirement for installation of geosynthetic liners including GCLs. However, it is not always that this requirement is fulfilled due to both the geological condition, for example, when a landfill has to be constructed on gravelly stratum, or when strict quality assurance/ quality control procedures are not specified or followed properly. The result of this study showed that GCLs may be able to perform well and maintain very low permittivity even when they are in direct contact with gravelly soil. Actually, the 
permittivity of GCLs on the subgrade of real gravelly soil may even be lower since the voids between the gravels are filled with finer soils. However, further study is necessary for evaluating the performance of the composite liner consists of geomembrane and GCL on gravelly soil because the stiffness of geomembrane may be an important factor that affects the distribution of bentonite and thus the integrity and permittivity of the GCL.

\section{Conclusions}

The permittivity of GCL specimens placed against large-particle granular materials was determined by laboratory experiments.

The permittivity of both needle-punched and glued GCLs decreased with the effective stress and remained very low. The effect of the size and shape of subgrade material on the permittivity of GCLs was more significant under lower effective stress but diminished as the effective stress increased.

The GCL was demonstrated to have a tremendous ability to conform to the surface of the subgrade and the bentonite redistributed accordingly. Larger particle size, more angular shape, and lower hydration effective stress would cause the bentonite to distribute less uniformly. The difference between the maximum and minimum thickness and mass per unit area of the GCL specimens were very significant. In particular, the difference in thickness was 1.5 to 2 times as much as the average thickness.

The thickness of the geotextile and the needle-punched fibers of the GCL were shown to have an effect on the distribution of the bentonite. Although the GCL with thinner geotextile and no needle-punched fibers resulted in lower permittivity, the bentonite in the GCL with thicker geotextile and the needle-punched fibers distributed more uniformly. It is concluded that reinforced GCLs should performed more consistently when installed on a gravel subgrade. It should be noted that these were short-term tests and the long-tem response still needs to be established.

\section{Acknowledgements}

The study was partly sponsored by the National Science Council of Taiwan, Republic of China through NSC90-2211-E-009-067 project grant. The authors thank Mr. Robert Trauger of CETCO and Mr. Kevin Wu of MEREX Co. for providing the GCL samples for this study.

\section{References}

Anderson, J.D., 1996. Are geosynthetic clay liners (GCLs) really equivalent to compacted clay liners? Geotechnical News 14 (2), 20-23. 
CETCO, 1998a. Bentomat ${ }^{\circledR}$ ST Certified Properties Technical Data Sheet, USA.

CETCO, 1998b. Claymax ${ }^{\circledR}$ 200R Certified Properties, USA.

Fox, P.J., De Battista, D.J., Chen, S.H., 1996. Bearing capacity of geosynthetic clay liners for cover soils of varying particle size. Geosynthetics International 3 (4), 447-461.

Fox, P.J., Triplett, E.J., Kim, R.H., Olsta, J.T., 1998. Field study of installation damage for geosynthetic clay liners. Geosynthetics International 5 (5), 491-520.

Fox, P.J., De Battista, D.J., Mast, D.G., 2000. Hydraulic performance of geosynthetic clay liners under gravel cover soils. Geotextiles and Geomembranes 18 (2000), 179-201.

Koerner, R.M., Narejo, D., 1995. Bearing capacity of hydrated geosynthetic clay liners. Journal of Geotechnical Engineering, ASCE 121 (1), 82-85.

Peggs, I.D., Olsta, J.T., 1998. A GCL and incompatible soil case history: a design problem. Proceedings of the 12th GRI Conference, Philadelphia, PA, USA, pp. 117-138.

Rowe, R.K., Orsini, C., 2002. Internal erosion of GCLs placed directly over fine gravel. Proceedings of the International Symposium on Geosynthetic Clay Barriers, Nuremberg, Germany, April, pp. 99-208.

Rowe, R.K., Orsini, C., 2003. Effect of GCL and subgrade type on internal erosion in GCLs. Geotextiles and Geomembranes 21 (1), 1-24.

Shan, H.-Y., Daniel, D.E., 1991. Result of laboratory tests on a geotextile/bentonite liner material. Proceedings of Geosynthetics '91, Industrial Fabrics Association, St. Paul, MN, pp. 517-535.

Stark, T.D., 1998. Bentonite migration in geosynthetic clay liners. Proceedings of the Sixth International Conference on Geosynthetics, IFAI, Atlanta, Georgia, USA, Vol. 1, pp. 315-320. 